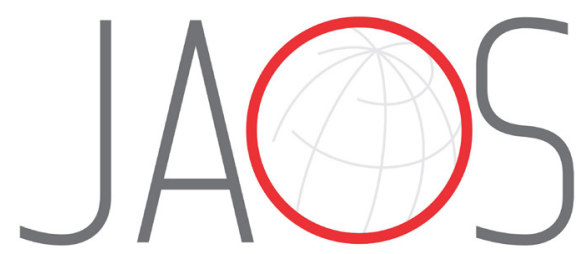

JOURNAL OF APPLIED ORAL SCIENCE

\title{
Effects of three silane primers and five adhesive agents on the bond strength of composite material for a computer-aided design and manufacturing system
}

\section{Abstract}

Ayano SHINOHARA ${ }^{1}$

Yohsuke TAIRA ${ }^{1}$

Michino SAKIHARA ${ }^{1}$

Takashi SAWASE ${ }^{1}$
Submitted: July 20, 2017 Modification: September 6, 2017 Accepted: October 22, 2017

Corresponding address: Yohsuke Taira Department of Applied Prosthodontics - Graduate School of Biomedical Sciences - Nagasaki University 1-7-1 Sakamoto, Nagasaki 852-8588 - Japan Phone: +81-95-819-7688 - Fax: +81-95-819-7689 e-mail: yohsuke@nagasaki-u.ac.jp
Objective: The objective of this study was to evaluate the effects of combinations of silane primers and adhesive agents on the bond strength of a composite block for a computer-aided design and manufacturing system. Material and Methods: Three silane primers [Clearfil Ceramic Primer (CP), Super-Bond PZ Primer (PZ), and GC Ceramic Primer II (GP)] were used in conjunction with five adhesive agents [G-Premio Bond (P-Bond), Repair Adhe Adhesive (R-Adhesive), Super-Bond D-Liner Dual (SB-Dual), Super-Bond C\&B (SB-Self), and SB-Dual without tributylborane derivative (SB-Light)]. The surface of a composite block (Gradia Block) was ground with silicon carbide paper. After treatment with a silane primer, a adhesive agent was applied to each testing specimen. The specimens were then bonded with a light-curing resin composite. After $24 \mathrm{~h}$, the shear bond strength values were determined and compared using a post hoc test ( $\alpha=0.05, n=8 /$ group). We also prepared control specimens without primer (No primer) and/or without adhesive agent (No adhesive). Results: PZ/SB-Dual and GP/SB-Dual presented the highest bond strength, followed by GP/P-Bond, CP/SB-Dual, $\mathrm{CP} / \mathrm{R}$-Adhesive, No primer/SB-Dual, GP/R-Adhesive, CP/P-Bond, No primer/RAdhesive, PZ/R-Adhesive, CP/SB-Self, PZ/P-Bond, PZ/SB-Self, and GP/SB-Self in descending order of bond strength. No primer/P-Bond, No primer/SB-Self, and all specimens in the SB-Light and No adhesive groups presented the lowest bond strengths. Conclusion: A dual-curing adhesive agent (SB-Dual) containing a tributylborane derivative in combination with a silane primer (GP or PZ) presents a greater bond strength between the composite block and the repairing resin composite than the comparators used in the study.

Keywords: Bond strength. CAD-CAM. Composite resin. Adhesive. 


\section{Introduction}

The advent of computer-aided design and computer-aided manufacturing (CAD/CAM) systems, the use of highly filled resin composite materials became increasingly common for crown restorations ${ }^{16}$. Despite the improvement of the mechanical properties of composite blocks for CAD/CAM systems over time ${ }^{8,13}$, partial fractures still occur occasionally on restorations in the oral environment. Strong bonding between the machine-milled composite blocks and the resin composite veneering materials is required to repair defects in resin composite restorations or to modify the esthetics of the monochromatic composite blocks using the layering technique ${ }^{15}$.

Ceramic repair systems and pre-treatment agents have improved the bond strength of resin-based materials to composite blocks ${ }^{4,6}$. Certain studies

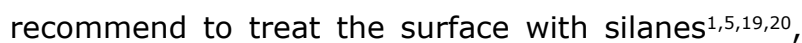
while others claim that silanization techniques do not increase bond strength ${ }^{22,23}$. When a silane primer and an adhesive agent were applied to the surface of a composite block, the bond strength was greater than that obtained through the use of a lithium disilicate glass ceramic or a feldspar ceramic ${ }^{3}$. Studies show that the combined use of a silane primer and a lightcuring adhesive agent is effective to increase the bond strength between the layers of a resin composite ${ }^{11,12}$. However, there is little information available on the effect of the type of polymerization initiator contained in the adhesive agent on the bond strength.

Masuhara ${ }^{14}$ (1969) developed a self-curing adhesive agent initiated with tributylborane (TBB) for dental treatment. The features of polymerization initiated by TBB are fundamentally different from those of the photoinitiators upon postpolymerization and interfacial initiation of polymerization ${ }^{10,21}$. Super-Bond D-Liner Dual (Sun Medical Co., Moriyama, Japan) is a commercially available adhesive agent that uses a dual-curing system containing a photoinitiator and TBB. Despite the reports of TBB being a useful initiator component ${ }^{9,17}$, it is not clear if dual-curing systems provide an added advantage vis-à-vis the bond strength of a composite block.

The objective of this study was to evaluate the bond strength between a composite block and the light-curing resin composite comprising five different adhesive agents (three light-curing systems, one self-curing system, and one dual-curing system) in conjunction with three silane primers. The null hypothesis was that there is no significant difference among the bond strengths for the different combinations of the adhesive agents and silane primers.

\section{Materials and methods}

\section{Shear bond strength tests}

The three silane primers ( $C P, P Z$, and $G P)$ and five adhesive agents (P-Bond, R-Adhesive, SB-Dual, SB-Self, and SB-Light) used are listed in Figure 1. The testing specimens consisted of 192 rectangular specimens $(8 \times 10 \times 3 \mathrm{~mm})$ that were cut from a composite block (Gradia Block, A3, GC Corp., Tokyo, Japan) using a diamond saw (IsoMet Low Speed Saw, Buehler, Lake Bluff, IL, USA), they were divided into 24 groups ( 15 combinations of 3 primers and 5 adhesive agents and 9 controls) of 8 specimens each. All specimens were ground with 600-grit silicon-carbide abrasive paper (BuehlerMet2, Buehler, Lake Bluff, IL, USA), rinsed by spraying with water for $10 \mathrm{~s}$, and air-dried. We attached a piece of masking tape with a circular hole of $2 \mathrm{~mm}$ in diameter to the surface of each specimen to delineate the bonding area (Figure $2)$. One microliter of each of the silane primer and adhesive agent was then applied to the specimens with a micropipette (Eppendorf AG, Hamburg, Germany) and gently air-blown. Except for SB-Self, the adhesive agents used were light-cured for $10 \mathrm{~s}$ using a lightemitting diode handpiece (power density 1,000 mW/ $\mathrm{cm}^{2}$; Pencure, J. Morita MFG. Corp., Tokyo, Japan). We also prepared control specimens without primer (No primer) and/or without adhesive agent (No adhesive).

We placed an acrylic ring (internal diameter: 4 $\mathrm{mm}$, height: $2 \mathrm{~mm}$ ) on the specimen and filled it with a light-curing resin composite (Gradia Direct, A3, GC Corp., Tokyo, Japan). The resin composite was then light-cured for $40 \mathrm{~s}$. The specimens were stored in the atmosphere for $30 \mathrm{~min}$ and then immersed in water at $37^{\circ} \mathrm{C}$ for $24 \mathrm{~h}$. Each specimen was embedded in an acrylic resin mold and placed in a shear-testing device (No. ISO/TR11405, Wago Industrial Ltd., Nagasaki, Japan). The shear bond strength of each specimen was determined using a universal testing machine (AGS-10kNG, Shimadzu Corp., Kyoto, Japan) at a cross-head speed of $0.5 \mathrm{~mm} / \mathrm{min}$.

The debonded surfaces of all specimens were observed with an optical microscope (SMZ-10, Nikon 
Corp., Tokyo, Japan) at a magnification of $\times 20$ to assess bond failure. Failure modes were categorized as adhesive failure at the interface between the composite block and veneered resin composite (Ad) and a combination of Ad and crack propagation ( $\mathrm{Cr}$ ) inside the composite block ( $\mathrm{Ad} / \mathrm{Cr})$.

\section{Scanning electron microscopy (SEM)}

In addition, a composite block was ground with 600-grit silicon-carbide abrasive paper, its surface was sputter-coated with gold (Ion Coater IB-3, Eiko Engineering Co. Ltd., Hitachinaka, Japan), then we observed it using a scanning electron microscope (JCM6000Plus, JEOL Ltd., Tokyo, Japan) at magnifications of $\times 1,000$ and $\times 10,000$.

\section{Statistical analysis}

The mean bond strength and standard deviation (SD) of all eight specimens were calculated for each test group. The reliability of the sample size and the assumption of homoscedasticity were confirmed using power analysis and Levene's test, respectively. The data were analyzed using analysis of variance (ANOVA) and a post hoc (Tukey-Kramer HSD) test, statistical significance was set at 0.05 .

\begin{tabular}{|c|c|c|c|}
\hline Name (abbreviation) & Component $^{*}$ & Manufacturer & Lot No. \\
\hline \multicolumn{4}{|l|}{ Resin composite } \\
\hline Gradia Block, A3 & $\begin{array}{l}\text { UDMA } 20 \% \text {, multifunctional methacrylate } 4 \% \text {, } \\
\text { organic-inorganic composite filler } 3 \% \text {, } \\
\text { silica-based powder } 73 \% \text {, others }\end{array}$ & GC Corp., Tokyo, Japan & $\begin{array}{l}1204101 \\
1205171\end{array}$ \\
\hline Gradia Direct, A3 & $\begin{array}{l}\text { UDMA, multifunctional methacrylate, } \\
\text { organic-inorganic composite filler, } \\
\text { silica-based powder, others }\end{array}$ & GC Corp. & $\begin{array}{l}1412031 \\
1506241\end{array}$ \\
\hline \multicolumn{4}{|l|}{ Silane primer } \\
\hline Clearfil Ceramic Primer (CP) & silane, phosphate monomer, ethanol & $\begin{array}{l}\text { Kuraray Noritake Dental } \\
\text { Inc., Tokyo, Japan }\end{array}$ & B60008 \\
\hline Super-Bond PZ Primer (PZ) & silane, phosphate monomer, MMA & $\begin{array}{l}\text { Sun Medical Co., } \\
\text { Moriyama, Japan }\end{array}$ & LS1 \\
\hline GC Ceramic Primer II (GP) & silane, phosphate monomer, methacrylate, ethanol & GC Corp. & 1409051 \\
\hline \multicolumn{4}{|l|}{ Adhesive agent } \\
\hline G-Premio Bond (P-Bond) & $\begin{array}{l}\text { 4-MET, phosphate monomer, thiophosphate } \\
\text { monomer, } \\
\text { dimethacrylate, acetone, water, photoinitiator }\end{array}$ & GC Corp. & 1411271 \\
\hline $\begin{array}{l}\text { Repair Adhe Adhesive } \\
\text { (R-Adhesive) }\end{array}$ & $\begin{array}{l}\text { UDMA, HEMA, TEGDMA, silica powder, } \\
\text { photoinitiator }\end{array}$ & GC Corp. & 1410081 \\
\hline $\begin{array}{l}\text { Super-Bond D-Liner Dual (SB- } \\
\text { Dual) }\end{array}$ & $\begin{array}{c}\text { Liquid: MMA, dimethacrylate, HEMA, 4-META, } \\
\text { photoinitiator } \\
\text { Catalyst V: TBB derivative }\end{array}$ & Sun Medical Co. & $\begin{array}{l}\text { LW1 } \\
\text { KW31F }\end{array}$ \\
\hline $\begin{array}{l}\text { Super-Bond C\&B without } \\
\text { polymer powder (SB-Self) }\end{array}$ & $\begin{array}{l}\text { Monomer liquid: MMA, 4-META } \\
\text { Catalyst V: TBB derivative }\end{array}$ & Sun Medical Co. & KR4 \\
\hline $\begin{array}{l}\text { SB-Dual without Catalyst V } \\
\text { (SB-Light) }\end{array}$ & $\begin{array}{c}\text { MMA, dimethacrylate, HEMA, 4-META, } \\
\text { photoinitiator }\end{array}$ & Sun Medical Co. & LW1 \\
\hline
\end{tabular}

*UDMA: urethane dimethacrylate, MMA: methyl methacrylate, 4-MET: 4-methacryloyloxyethyl trimellitic acid, HEMA: 2-hydroxyethyl methacrylate, TEGDMA: triethyleneglycol dimethacrylate, 4-META: 4-methacryloyloxyethyl trimellitate anhydride, TBB: tributylborane

Figure 1- Resin composites, silane primers, and adhesives agents used for shear bond strength tests

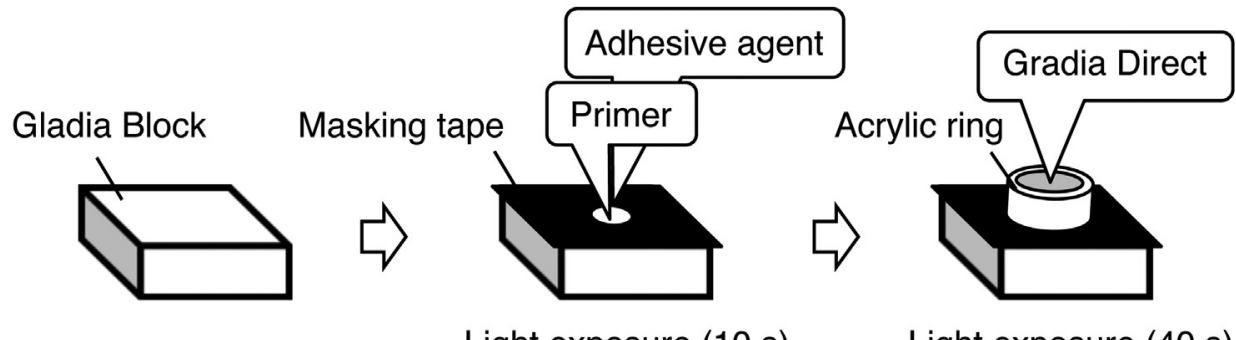

Light exposure (10 s) Light exposure (40 s)

Figure 2- Schematic illustration of the bonding procedure 


\section{Results}

\section{Shear bond strength}

The results of a two-way ANOVA indicate that the bond strength was significantly influenced by both the primer $(P=0.0005)$ and the adhesive agent $(P<0.0001)$ independently and that their interaction did not reach a level of statistical significance (Table 1 ).

The mean bond strength ranged from 15.2 to 42.2 MPa (Figure 3, Table 2). PZ/SB-Dual and GP/SB-Dual presented the greatest bond strength, however no significant differences were observed among 14 groups (PZ/SB-Dual, GP/SB-Dual, GP/P-Bond, CP/SB-Dual, $C P / R-A d h e s i v e$, No primer/SB-Dual, GP/R-Adhesive, CP/P-Bond, No primer/R-Adhesive, PZ/R-Adhesive, CP/SB-Self, PZ/P-Bond, PZ/SB-Self, and GP/SB-Self).
No primer/P-Bond, No primer/SB-Self, and all the SBLight and No adhesive groups presented the lowest bond strength. Within each adhesive agent group, no statistically significant difference was observed among the No primer, CP, PZ, and GP specimens.

Regarding the mode of failure when using R-Adhesive or SB-Dual, a greater number of specimen failures were in the category of Ad/Cr. Except for two specimens, all the specimens in the No adhesive, P-Bond, SB-Self, and SB-Light specimen groups presented only Ad.

\section{Scanning electron microscopy}

Figure 4 shows SEM images of the ground CAD/ CAM composite surface. Numerous supramicron and submicron particles of the hybrid filler can be observed.

Table 1- Two-way ANOVA results

\begin{tabular}{cccccc}
\hline Source of variation & d.f. & Sum of squares & Mean square & F-value & P-value \\
\hline Silane primer & 3 & 980.281 & 326.76 & 6.266 & 0.0005 \\
Adhesive agent & 5 & $9,858.206$ & $1,971.641$ & 37.812 & $<0.0001$ \\
$\begin{array}{c}\text { Silane primer/ } \\
\text { Adhesive agent }\end{array}$ & 15 & 928.831 & 61.922 & 1.187 & 0.2857 \\
Residual & 168 & $8,759.852$ & 52.142 & & \\
\hline
\end{tabular}

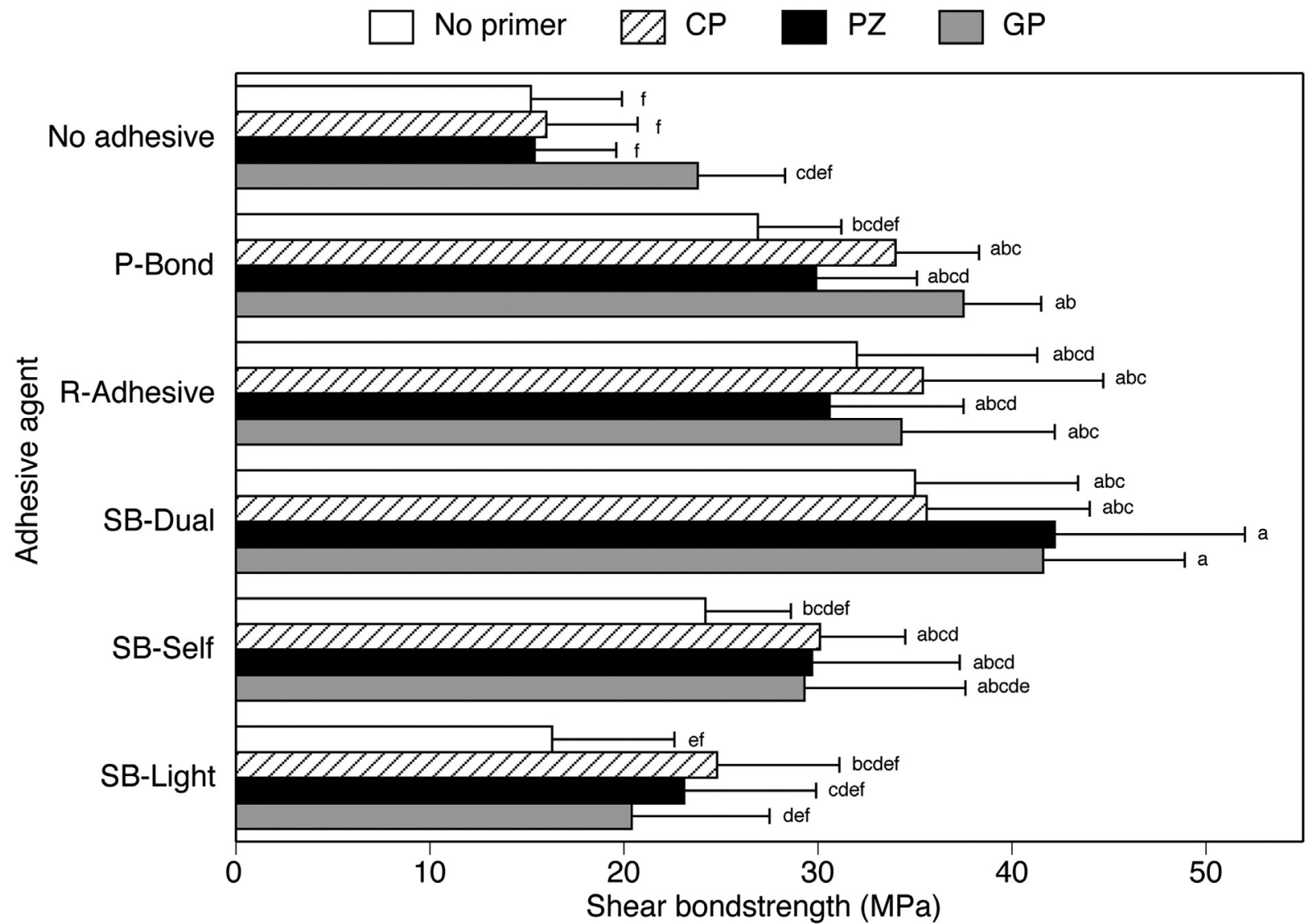

Figure 3- Results of shear bond testing. Identical letters $(a, b, c, d, e, f)$ indicate that the difference between values is not statistically significant $(p \geq 0.05)$ 
Table 2- Shear bond strengths and failure modes observed after shear bond testing

\begin{tabular}{|c|c|c|c|c|c|c|c|c|}
\hline & \multicolumn{4}{|c|}{ Mean (SD)* (MPa) } & \multicolumn{4}{|c|}{ Failure mode ${ }^{* *}$ (number of specimens) } \\
\hline & No primer & CP & $\mathbf{P Z}$ & GP & No primer & CP & $\mathbf{P Z}$ & GP \\
\hline $\begin{array}{c}\text { No } \\
\text { adhesive }\end{array}$ & $15.2(4.7)^{f}$ & $16.0(6.2)^{f}$ & $15.4(4.2)^{f}$ & $23.8(4.5)^{\text {cdef }}$ & $\operatorname{Ad}(8)$ & $\operatorname{Ad}(8)$ & $\operatorname{Ad}(8)$ & $\operatorname{Ad}(8)$ \\
\hline P-Bond & $26.9(4.3)^{\text {bcdef }}$ & $34.0(6.0)^{\mathrm{abc}}$ & $29.9(5.2)^{\mathrm{abcd}}$ & $37.5(4.0)^{\mathrm{ab}}$ & $\operatorname{Ad}(8)$ & $\operatorname{Ad}(8)$ & $\operatorname{Ad}(8)$ & $\begin{array}{c}\operatorname{Ad}(7) \\
\operatorname{Ad} / \operatorname{Cr}(1)\end{array}$ \\
\hline R-Adhesive & $32.0(9.3)^{\mathrm{abcd}}$ & $35.4(11.8)^{\mathrm{abc}}$ & $30.6(6.9)^{\mathrm{abcd}}$ & $34.3(7.9)^{\mathrm{abc}}$ & $\begin{array}{c}\operatorname{Ad}(4) \\
\operatorname{Ad} / \operatorname{Cr}(4)\end{array}$ & $\begin{array}{c}\operatorname{Ad}(1) \\
\operatorname{Ad} / \operatorname{Cr}(7)\end{array}$ & $\begin{array}{c}\operatorname{Ad}(5) \\
\operatorname{Ad} / \operatorname{Cr}(3)\end{array}$ & $\begin{array}{c}\operatorname{Ad}(4) \\
\operatorname{Ad} / C r(4)\end{array}$ \\
\hline SB-Dual & $35.0(8.4)^{\mathrm{abc}}$ & $35.6(9.9)^{\mathrm{abc}}$ & $42.2(9.8)^{\mathrm{a}}$ & $41.6(7.3)^{\mathrm{a}}$ & $\begin{array}{c}\operatorname{Ad}(5) \\
\operatorname{Ad} / \operatorname{Cr}(3)\end{array}$ & $\begin{array}{l}\mathrm{Ad}(4) \mathrm{Ad} / \\
\mathrm{Cr}(4)\end{array}$ & $\begin{array}{c}\operatorname{Ad}(1) \\
\operatorname{Ad} / \operatorname{Cr}(7)\end{array}$ & $\mathrm{Ad} / \mathrm{Cr}(8)$ \\
\hline SB-Self & $24.2(4.4)^{\text {bcdef }}$ & $30.1(6.3)^{\mathrm{abcd}}$ & $29.7(7.6)^{\mathrm{abcd}}$ & $29.3(8.3)^{\text {abcde }}$ & $\operatorname{Ad}(8)$ & $\operatorname{Ad}(8)$ & $\begin{array}{c}\operatorname{Ad}(7) \\
\operatorname{Ad} / \operatorname{Cr}(1)\end{array}$ & $\operatorname{Ad}(8)$ \\
\hline SB-Light & $16.3(6.3)^{\text {ef }}$ & $24.8(8.9)^{\text {bcdef }}$ & $23.1(6.8)^{\text {cdef }}$ & $20.4(7.1)^{\text {def }}$ & $\operatorname{Ad}(8)$ & $\operatorname{Ad}(8)$ & $\operatorname{Ad}(8)$ & $\operatorname{Ad}(8)$ \\
\hline
\end{tabular}

*Identical small letters indicate values that are not statistically different $(p \geq 0.05)$

${ }^{* *} \mathrm{Ad}$ : Adhesive failure at the interface between the composite block and the veneered resin composite, $\mathrm{Ad} / \mathrm{Cr}$ : Combinations of adhesive failure and crack propagation inside the composite block.
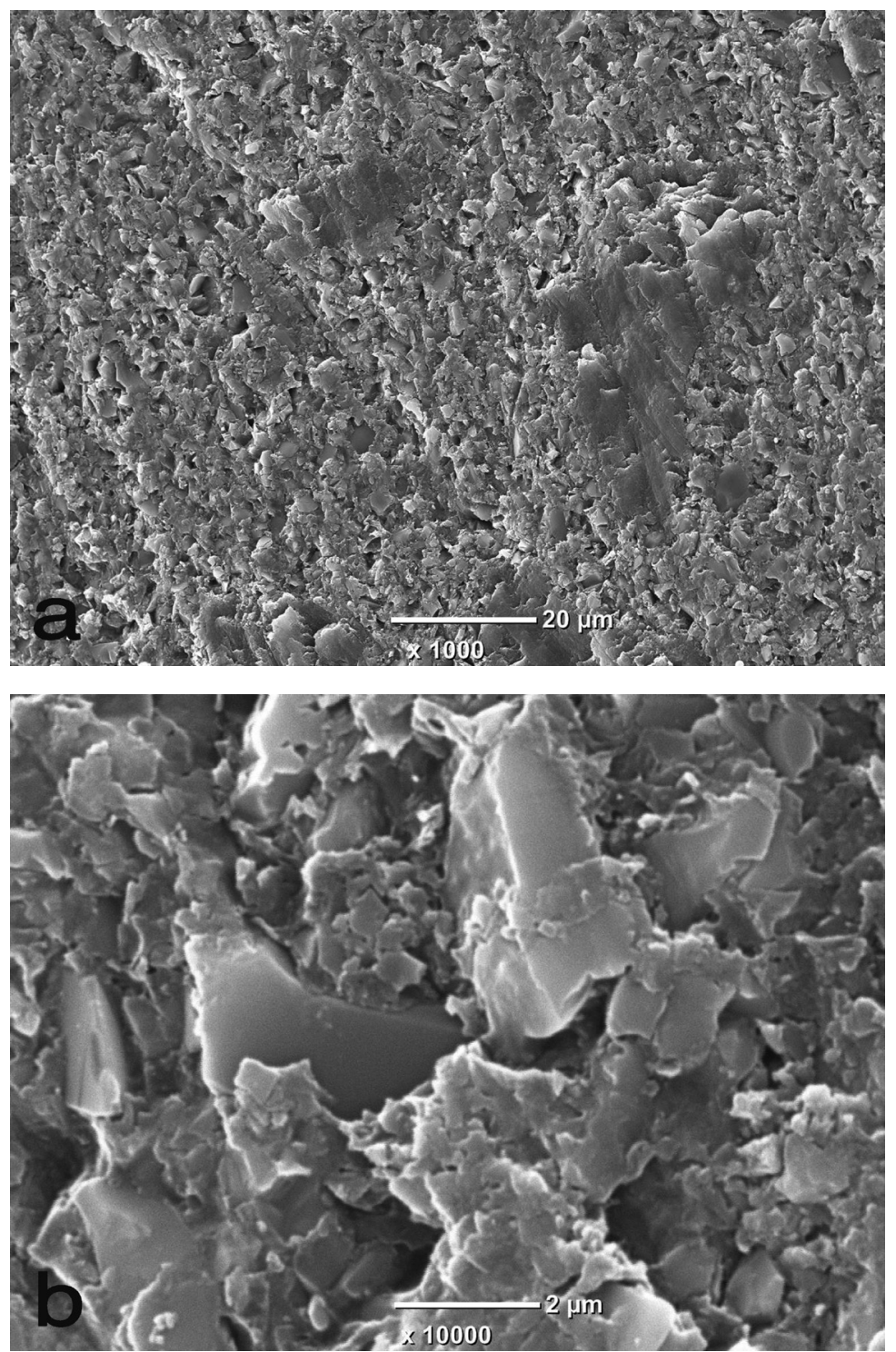

Figure 4- Scanning electron micrograph of a CAD/CAM composite specimen ground with 600-grit silicon-carbide abrasive paper. Original magnification: (a) $\times 1,000$ and (b) $\times 10,000$ 
The surfaces of the filler particles were relatively smooth against the roughened matrix resin.

\section{Discussion}

This study assessed the effects of three silane primers and five types of coupling agents on bonding between a composite block and a light-curing resin composite. The results of two-way ANOVA indicated that the addition of coupling agents and silane primers made a statistically significant difference on the bond strength. Therefore, the null hypothesis was rejected. ANOVA also indicated that the contribution from coupling agents to the bond strength was greater than the silane primers.

Both GP/P-Bond and GP/R-Adhesive were applied according to the manufacturer's protocol for repairing resin composite restorations. The reported shear bond strength ${ }^{19,22}$ between a resin composite and six different CAD/CAM polymer materials were lower than those of GP/P-Bond and GP/R-Adhesive. Therefore, the relatively high bond strength presented by GP/ SB-Dual in this study, is notable when compared to both GP/P-Bond and GP/R-Adhesive. Comparing the molecular weight of methyl methacrylate (MMA) to the molecular weights of the dimethacrylates contained in P-Bond and R-Adhesive, MMA presents low weight. This difference in monomer composition could be one of the factors affecting the diffusion of the coupling agents into the slightly roughened matrix resin (Figure 4 ).

The different bond strengths generated by the three MMA-based adhesive agents (SB-Dual, SB-Self, and SB-Light) suggest the presence of other factors not related to MMA. SB-Dual contains both a TBB derivative and a photoinitiator. SB-Light (containing no TBB derivative) and SB-Self (containing no photoinitiator) were used as controls to evaluate the role of the TBB derivative. The greater bond strengths obtained from SB-Dual suggest cooperative effects between TBB and the photoinitiator, SB-Self and SB-Light presented lower values. This supports the findings of a previous study, which reports that the combined used camphorquinone and TBB was effective to decrease residual monomer and to promote the postpolymerization of the resin ${ }^{9}$. The degree of conversion of the polymerized Gradia composite, measured by Fourier transform near infrared spectroscopy, is reported to be around $40-50 \%$.
Considering this, we speculate that the unpolymerized methacryloyl groups remaining in the Gradia Block get chemically bonded to the methacrylates in the primers and coupling agents by radical polymerization.

The composite block used contained $73 \%$ inorganic filler and 3\% organic-inorganic composite filler. Silane coupling agents react with inorganic components such as silica to form siloxane bonds; they also copolymerize with methacrylates ${ }^{2,18}$. However, in this study we did not obtain a high bond strength using a silane primer alone ( $\mathrm{CP} / \mathrm{No}$ adhesive, $\mathrm{PZ} / \mathrm{No}$ adhesive, or GP/No adhesive). We hypothesize that the inorganic filler particles had already been treated with silane coupling agents during the manufacture process, therefore, the substrate surface contained few exposed inorganic components. This could be the reason for the limited effect of the silane primers on bond strength.

The mode of failure tended to shift from $\mathrm{Ad}$ to $\mathrm{Ad} / \mathrm{Cr}$ as the bond strength increased (Table 2). R-Adhesive and SB-Dual presented more $\mathrm{Ad} / \mathrm{Cr}$, indicating a higher bond strength, than the No adhesive, P-Bond, SB-Self, and SB-Light specimens. Neither the composite block nor the veneering resin composite presented complete cohesive failure, suggesting that the adhesive force was inferior to the cohesive strength of the resin composite materials. Thus, the improvement on the adhesive force seems to be a worthy subject for further research

Clinically, a number of factors, such as aging of restorative material in the presence of saliva, plaque, pellicle, and biting force, would influence the bond strength. The bond strength testing performed in this study does not reflect all possible contributory factors that might occur in clinical settings. We used a micropipette to control the amount of primer and coupling agent applied on the specimen, clinicians usually use other applicators, such as a mini-sponge or a brush; these different application methods may affect adhesive bonding. However, the $24 \mathrm{~h}$ bond strength obtained is useful as a preclinical screening tool. Although long-term clinical observation is needed to validate the findings of this study, practitioners, when repairing or veneering CAD/CAM composite restorations, should consider that strong bonding of a composite block might not be achieved without the use of a coupling agent containing a suitable polymerization initiator. 


\section{Conclusions}

Within the limitations of this study, we conclude that the combination of a silane primer (GP or PZ) and a dual-curing adhesive agent (SB-Dual) improves the bond strength between a composite block and a lightcuring resin composite. Furthermore, the contribution of the coupling agent to the bond strength is greater than that of the silane primers.

\section{References}

1- Arao N, Yoshida K, Sawase T. Effects of air abrasion with alumina or glass beads on surface characteristics of CAD/CAM composite materials and the bond strength of resin cements. J Appl Oral Sci. 2015;23(6):629-36.

2- Bowen RL. Properties of a silica-reinforced polymer for dental restorations. J Am Dent Assoc. 1963;66:57-64.

3- Duzyol M, Sagsoz O, Polat Sagsoz N, Akgul N, Yildiz M. The effect of surface treatments on the bond strength between CAD/CAM blocks and composite resin. J Prosthodont. 2016;25(6):466-71.

4- Elsaka SE. Repair bond strength of resin composite to a novel CAD/CAM hybrid ceramic using different repair systems. Dent Mater J. $2015 ; 34(2): 161-7$

5- Elsaka SE. Influence of surface treatments on bond strength of metal and ceramic brackets to a novel CAD/CAM hybrid ceramic material. Odontology. 2016;104(1):68-76.

6- Gilbert S, Keul C, Roos M, Edelhoff D, Stawarczyk B. Bonding between CAD/CAM resin and resin composite cements dependent on bonding agents: three different in vitro test methods. Clin Oral Investig. 2016;20(2):227-36.

7- Hadis M, Leprince JG, Shortall AC, Devaux J, Leloup G, Palin WM. High irradiance curing and anomalies of exposure reciprocity law in resin-based materials. J Dent. 2011;39(8):549-57.

8- Harada A, Nakamura K, Kanno T, Inagaki R, Örtengren U, Niwano $Y$, et al. Fracture resistance of computer-aided design/computer-aided manufacturing-generated composite resin-based molar crowns. Eur ] Oral Sci. 2015;123(2):122-9.

9- Hirabayashi C. Studies on MMA-TBB resin II. The effect of dual use of TBB and other initiators on polymerization of PMMA/MMA resin. Dent Mater J. 2003;22(1):48-55.
10- Hirabayashi C, Imai Y. Studies on MMA-TBB resin I. Comparison of TBB and other initiators in the polymerization of PMMA/MMA resin. Dent Mater J. 2002;21(4):314-21.

11- Hisamatsu N, Atsuta M, Matsumura $\mathrm{H}$. Effect of silane primers and unfilled resin bonding agents on repair bond strength of a prosthodontic microfilled composite. J Oral Rehabil. 2002;29(7):644-8.

12- Hisamatsu N, Tanoue N, Yanagida H, Atsuta M, Matsumura H. Twenty-four hour bond strength between layers of a highly loaded indirect composite. Dent Mater J. 2005;24(3):440-6.

13- Lauvahutanon S, Takahashi H, Shiozawa M, Iwasaki N, Asakawa Y, Oki M, et al. Mechanical properties of composite resin blocks for CAD/ CAM. Dent Mater J. 2014;33(5):705-10.

14- Masuhara E. On the chemistry of a new adhesive plastic filling material. Dtsch Zahnärztl Z. 1969;24(7):620-8.

15- Rocca GT, Bonnafous F, Rizcalla N, Krejci I. A technique to improve the esthetic aspects of CAD/CAM composite resin restorations. J Prosthet Dent. 2010;104(4):273-5.

16- Ruse ND, Sadoun MJ. Resin-composite blocks for dental CAD/CAM applications. J Dent Res. 2014;93(12):1232-4.

17- Shinohara A, Taira Y, Sawase T. Effects of tributylboraneactivated adhesive and two silane agents on bonding computer-aided design and manufacturing (CAD/CAM) resin composite. Odontology. 2017;105(4):437-42.

18- Söderholm KJ, Shang SW. Molecular orientation of silane at the surface of colloidal silica. J Dent Res. 1993;72(6):1050-4.

19- Stawarczyk B, Krawczuk A, Ilie N. Tensile bond strength of resin composite repair in vitro using different surface preparation conditionings to an aged CAD/CAM resin nanoceramic. Clin Oral Investig. 2015;19(2):299-308.

20- Stawarczyk B, Trottmann A, Hämmerle CHF, Özcan M. Adhesion of veneering resins to polymethylmethacrylate-based $C A D / C A M$ polymers after various surface conditioning methods. Acta Odontol Scand. 2013;71(5):1142-8.

21- Taira Y, Imai Y. Review of methyl methacrylate (MMA)/tributylborane (TBB)-initiated resin adhesive to dentin. Dent Mater J. 2014;33(3):291304.

22- Wiegand A, Stucki L, Hoffmann R, Attin T, Stawarczyk B. Repairability of CAD/CAM high-density PMMA- and composite-based polymers. Clin Oral Investig. 2015;19(8):2007-13.

23- Zaghloul H, Elkassas DW, Haridy MF. Effect of incorporation of silane in the bonding agent on the repair potential of machinable esthetic blocks. Eur J Dent. 2014;8(1):44-52. 